\title{
Lysine methyltransferase SETD6 modifies histones and non-histone proteins
}

\author{
Olivier Binda ${ }^{1, *}$ \\ ${ }^{1}$ Newcastle Cancer Centre at the Northern Institute for Cancer Research, Newcastle University, Newcastle upon Tyne, England \\ ${ }^{*}$ Correspondence should be addressed to: olivier.binda@mail.mcgill.ca.
}

\begin{abstract}
Although central to regulating the access to genetic information, most lysine methyltransferases remain poorly characterised relative to other family of enzymes. Herein, we report new substrates for the lysine methyltransferase SETD6. Based on the SETD6catalysed site on the histone variant $\mathrm{H} 2 \mathrm{AZ}$, we identified similar sequences in the canonical histones $\mathrm{H} 2 \mathrm{~A}$, $\mathrm{H} 3$, and $\mathrm{H} 4$ that are modified by SETD 6 in vitro, and putative non-histone substrates. We herein expend the repertoire of substrates for methylation by SETD6.
\end{abstract}

\section{INTRODUCTION}

Histone $\mathrm{H} 3$ lysine residues were found to be methylated over fifty years ago $(1,2)$. However, it was not until 2000 that the first mammalian histone lysine methyltransferase was discovered (3). The latest human genome annotation predicts over 60 lysine methyltransferases (KMTs) based on sequence similarities with either a SET or a seven $\beta$-strand catalytic domain (4). However, most of these enzymes remain uncharacterized or poorly studied. Thus, important questions regarding the biological relevance and biochemical properties of these enzymes remain unanswered. Importantly, several histone KMTs also methylate non-histone substrates, such as the tumour suppressors p53 (5-7), ING2 (8), and pRB (9), as well as chromatin proteins such as DNMT1 (10), $\mathrm{HP} 1 \mathrm{a} / \beta / \gamma^{(11)}$, RUVBL1 (12), and RUVBL2 (13).

The methyltransferase SETD6 mono-methylates the NFKB subunit RelA at lysine 310 (K310me1) (14), the histone variant $\mathrm{H} 2 \mathrm{AZ}$ at lysine $7\left(\mathrm{~K} 7^{\mathrm{me} 1}\right){ }^{(15)}$, and the kinase PAK4 (16). The expression of SETD6 is amplified in about $10 \%$ of cases of breast cancer according to a study using a patient xenograft model (17) and is required for cellular proliferation in both $\mathrm{ER}^{+}$and $\mathrm{ER}^{-}$ breast cancer cell models (18), suggesting an important role in driving breast cancer progression. Indeed, SETD6 was recently found to associate with the cytoskeleton protein VIM (19), which is involved in epithelial to mesenchymal transition (EMT), cellular attachment, migration, and signalling, suggesting a role in metastasis.

Much like classical signal transduction events involve phospho-dependent protein-protein binding, chromatin signalling events implicate post-translational modifications in the regulation of macro-molecules interactions. For example, lysine methylation of histones lysine residues serves as landing pads for chromatin proteins, which are referred to as histone mark readers or simply readers, thereby nucleating enzymatic complexes that modify and remodel chromatin to regulate access to genetic information.

Herein, we demonstrate that recombinant SETD6 methylates canonical histones $\mathrm{H} 2 \mathrm{~A}, \mathrm{H} 3$, and $\mathrm{H} 4$, as well as linker histones $\mathrm{H} 1$ and the non-histone protein ING2 in vitro, and identify several putative novel substrates, including chromatin proteins and other lysine methyltransferases.

\section{RESULTS}

We previously identified 2 mono-methylation sites on the histone variant H2AZ catalysed by SETD6 (15). Interestingly, these modified sites, H2AZK4me1 and $\mathrm{H} 2 \mathrm{AZK} 7^{\mathrm{me}}$, are similar. Both modified lysine residues are preceded by a small amino acid (alanine or glycine) at position -2 and a glycine at position -1 (Table 1). Examination of canonical histone tails revealed similar sequences in histones $\mathrm{H} 2 \mathrm{~A}, \mathrm{H} 3$, and $\mathrm{H} 4$, and identification of a putative SETD6 methylation consensus motif $A / G / R K^{m e}{ }^{1} A / G G$ (Table 1).

Table 1: SETD6 consensus motif. Based on H2AZ methylation sites by SETD6, putative modification sites were identified in canonical histones $\mathrm{H} 2 \mathrm{~A}, \mathrm{H} 3$, and $\mathrm{H} 4$.

\begin{tabular}{lrrrrrrrr}
\hline Histone & \multicolumn{1}{c}{ Consensus } \\
& -3 & -2 & -1 & 0 & +1 & +2 & +3 \\
H2AZ & A & G & G & $\mathrm{K}^{4}$ & A & G & K \\
H2AZ & K & A & G & $\mathrm{K}^{7}$ & D & S & G \\
H2A & G & R & G & K $^{5}$ & Q & G & G \\
H3 & T & G & G & $\mathrm{K}^{14}$ & A & P & R \\
H4 & G & R & G & $\mathrm{K}^{5}$ & G & G & K \\
H4 & G & L & G & $\mathrm{K}^{12}$ & G & G & A \\
& • & $\cdot$ & $\star$ & $\star$ & & : & . \\
& & &
\end{tabular}

To test whether SETD6 could methylate these other histones, we used a mixture of purified calf thymus histones as substrates. Interestingly, SETD6 was capable of modifying the linker $\mathrm{H} 1$ histones as well as the canonical histones $\mathrm{H} 2 \mathrm{~A}, \mathrm{H} 3$, and $\mathrm{H} 4$ (Figure 1). As a positive control, we used SET7, which is known 
to methylate $\mathrm{H} 3$ (20), and $\mathrm{H} 1$ histones (21). As a negative control, GST alone was used and as expected GST had no detectable methyltransferase activity on histones (Figure 1).
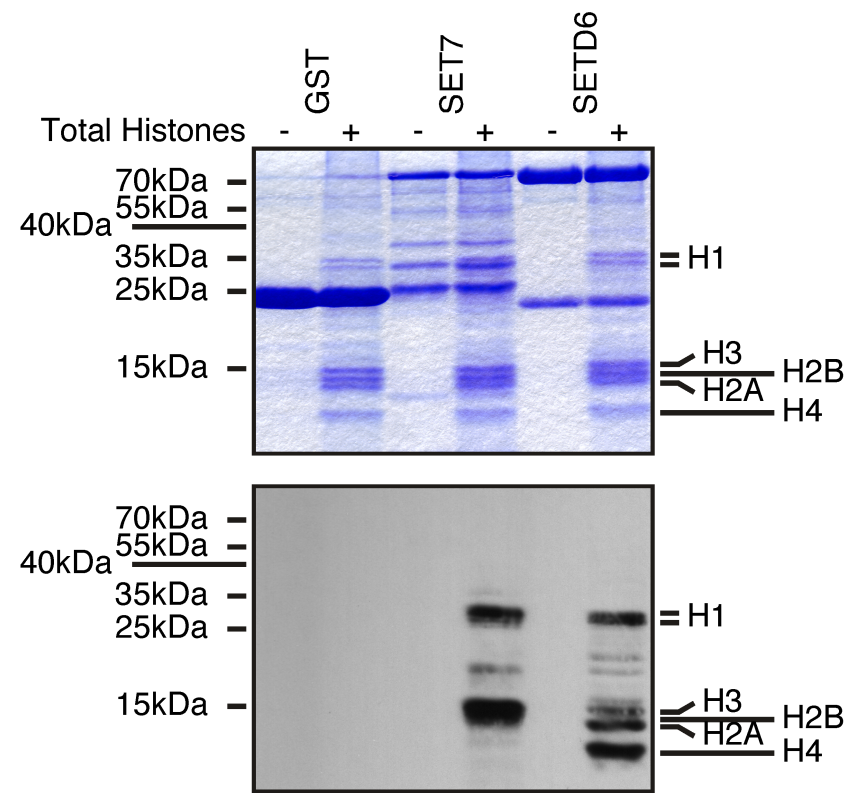

Figure 1: SETD6 methylates histones. Recombinant KMTs were used to modify histones isolated from calf thymus in the presence of ${ }^{3} \mathrm{H}-\mathrm{SAM}$. Samples were analysed by SDS-PAGE, then either stained with Coomassie (top panel) or transferred to PVDF membrane and autoradiographed (bottom panel).

To confirm the SETD6-catalysed methylation sites on canonical histones, the first 50 amino acid residues of $\mathrm{H} 2 \mathrm{~A}, \mathrm{H} 3$, and $\mathrm{H} 4$ were fused to the amino terminus of GST to leave the histone tail free at the amino terminus and generate $\mathrm{H}_{2} \mathrm{~A}_{1-50}-\mathrm{GST}, \mathrm{H} 3_{1-50}-\mathrm{GST}$, and $\mathrm{H} 4_{1-50-\mathrm{GST}}$. Then the predicted sites (Table 1) were converted to arginine by site-directed mutagenesis. The affinity purified recombinant proteins were then used for in vitro KMT assays with SETD6. In agreement with previous experiments showing that SETD6 modifies canonical histones (Figure 1), SETD6 methylated recombinant histone tails from $\mathrm{H} 2 \mathrm{~A}, \mathrm{H} 3$, and $\mathrm{H} 4$ (Figure 2A). Importantly, mutation of the GK motifs reduced drastically the methylation of $\mathrm{H} 2 \mathrm{~A}$ and $\mathrm{H} 3$ by SETD6 (Figure 2A). However, single mutation of $\mathrm{H} 4$ at $\mathrm{K} 5$ or $\mathrm{K} 12$ only minimally reduced methylation by SETD6 (Figure 2A).

Since $\mathrm{H} 4$ methylation seemed stronger (Figure 1), and to further investigate the methylation of $\mathrm{H} 4$ by SETD6, methyltransferase assays on $\mathrm{H} 4$ peptides $\mathrm{H} 4_{1-20}$ and $\mathrm{H} 4_{10-31}$ were performed and confirmed that SETD6 methylates H4 (Figure 2B). Interestingly, SETD6 methylated $\mathrm{H}_{10-31}$ better than the $\mathrm{H}_{1-20}$ peptide, while methylation at $\mathrm{K} 20$ (K20 ${ }^{\mathrm{me}} 1, \mathrm{~K} 2 \mathrm{O}^{\mathrm{me} 2}$, or $\mathrm{K} 2 \mathrm{O}^{\mathrm{me}} 3$ ) impaired this effect (Figure 2B), suggesting that SETD6 modifies H4K20 in addition to H4K12 or other site(s), such as H4K16 or H4K31 (Figure 2C).
Alternatively, these results may suggest that there is a cross-talk between H4K20me and the SETD6-catalysed methylation site(s).

A)

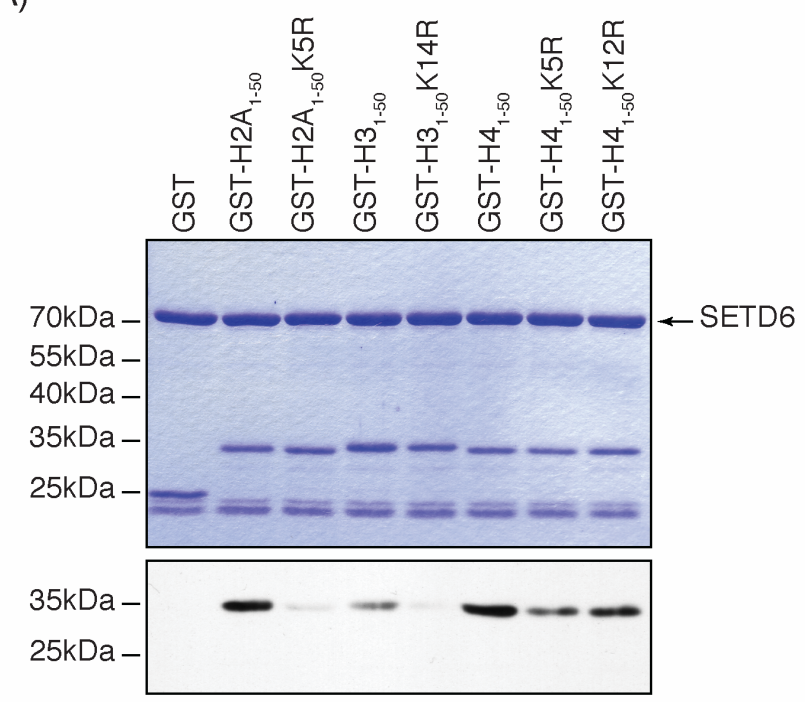

B)

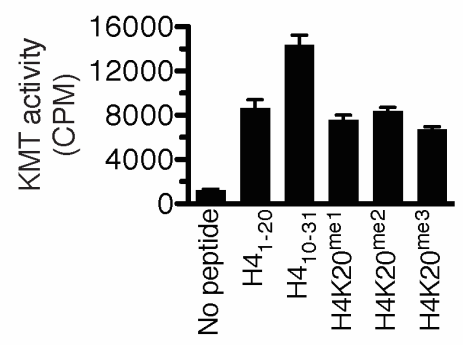

C)

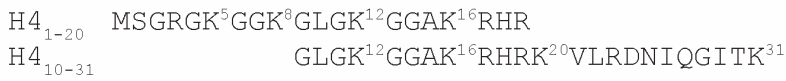

Figure 2: SETD6 methylates GK motifs in canonical histones. (A) SETD6 was used to methylate the indicated recombinant histone tails. Samples were analysed by SDS-PAGE, then either stained with Coomassie (top panel) or transferred to PVDF membrane and autoradiographed (bottom panel). (B) KMT assays were performed with SETD6 on $\mathrm{H} 4$ peptides. (C) Sequence of $\mathrm{H} 4$ peptides used in panel $B$ with each lysine numbered.

Several KMT, including SETD6, modify non-histone proteins. We thus searched for the GKDS motif in protein sequence repositories and identified several putative SETD6 substrates (Table 2 and S1), including the ATPase RUVBL1, which is modified by the H3K9 methyltransferases G9A and GLP (12). Importantly, some putative SETD6 substrates (AHNAK2, ERICH3, and MDN1) were found in the PhosphoSitePlus mass spectrometric database to be methylated at the predicted site (22) (Table S1). A similar search using the H4K5 and H4K12 motif GKGG also yielded several putative substrates for SETD6, such as the chromatin remodeller BRG1 (GK ${ }^{1029} \mathrm{GG}$ ) and the HBO1 acetyltransferase subunit JADE2 (GK $\left.{ }^{638} \mathrm{GG}\right)$. 
Table 2: Novel SETD6 putative substrates. The GKDS motif from H2AZ was used to identify novel substrates for SETD6.

\begin{tabular}{|c|c|c|}
\hline Substrate & Site & Function \\
\hline AHR & $\mathrm{GK}^{438} \mathrm{DS}$ & Nuclear receptor \\
\hline $\mathrm{APAF} 1$ & $\mathrm{GK}^{100} \mathrm{DS}$ & Apoptotis \\
\hline CDKN2C & $\mathrm{GK}^{160} \mathrm{DS}$ & CDK4 inhibitor p18 INK4C \\
\hline GREB1 & $\mathrm{GK}^{278} \mathrm{DS}$ & Proliferation \\
\hline KDM5A & $\mathrm{GK}^{1504} \mathrm{DS}$ & Demethylase \\
\hline MYST4 & $\mathrm{GK}^{393} \mathrm{DS}$ & Acetyltransferase \\
\hline RBBP 8 & $\mathrm{GK}^{426} \mathrm{DS}$ & pRB-binding protein \\
\hline RUVBL1 & $\mathrm{GK}^{422} \mathrm{DS}$ & Chromatin remodelling \\
\hline SMYD4 & $\mathrm{GK}^{63} \mathrm{DS}$ & Putative KMT \\
\hline SUV420H1 & $\mathrm{GK}^{864} \mathrm{DS}$ & $\mathrm{H} 4 \mathrm{~K} 20 \mathrm{KMT}$ \\
\hline
\end{tabular}

Herein, we found that SETD6 methylates histones $\mathrm{H} 2 \mathrm{~A}, \mathrm{H} 3$, and $\mathrm{H} 4$ on lysine residues within an $\mathrm{A} / \mathrm{G} /$ $\mathrm{RGK}^{\mathrm{me}}{ }^{1} \mathrm{~A} / \mathrm{GG}$ consensus motif.

\section{DISCUSSION}

Proteomic studies have identified post-translational modifications on histones and non-histone proteins, but the enzymatic activities depositing these modifications remain largely unknown. There is a dire need to identify PTMs to understand how proteins are regulated, but more importantly to identify the enzymes catalysing these biochemical events. To this end, we have in the past designed an unbiased chemical-biology approach to tag novel KMT substrates (23). However, traditional biochemical studies are still required to investigate and validate novel post-translational modifications.

The H3K14me1 mark was reported to occur in both human and mouse $(24,25)$, supporting the existence of the modification in cells. We have herein identified the first KMT capable of modifying this site in vitro. Further work will be required to validate the role of SETD6 in the catalysis of H3K14me1 in cells and the function of this mark.

Interestingly, $\mathrm{H} 4 \mathrm{~K} 12^{\mathrm{me} 3}$ (22), $\mathrm{H} 4 \mathrm{~K} 16^{\mathrm{me} 3} \quad(22,24)$, and H4K31me1 (26) were detected by mass spectrometry. However, no other reference to these modifications appear in the current literature. H4K5 was recently found to be methylated by SMYD3 (27).

Although mono-methylation events on the linker histone $\mathrm{H} 1 \mathrm{H} 1 \mathrm{~F} 0$ was reported at $\mathrm{K} 12, \mathrm{~K} 59$, K82, K102, $\mathrm{K} 108$, and K155 (22, 28), these sites do not share similarities with the SETD6 consensus motif, suggesting that SETD6 modifies non-GKDS sequences. Indeed, SETD6 methylates RelA at the non-GKDS site FK310SI (14). In addition, SETD6 can methylate the histone mark reader ING2 in vitro (Figure S1) and PAK4 (16), both of which do not contain any GKDS-like motif.

Together, the in vitro data provided here identifies SETD6 as a likely candidate for the methylation of reported events on H3K14, H4K5, H4K12, H4K16, and H4K31. In addition, we identified several putative non-histone protein substrates for SETD6.

\section{METHODS}

Plasmids. The modified pGEX plasmid with an engineered multi-cloning site at the $\mathrm{N}$-terminus of the GST coding sequence was described previously (15). The cDNA of histones $\mathrm{H} 2 \mathrm{~A}, \mathrm{H} 3$, and $\mathrm{H} 4$ was amplified by PCR from reverse transcribed total RNA and inserted in frame with GST using restriction endonucleases and T4 DNA ligase (NEB).

Recombinant protein expression and purification. Essentially, BL21 DE3 competent bacteria (Stratagene) were transformed with pGEX plasmids. Single colonies were picked and grown in 2YT media. Expression of GST-fusion proteins was induced with $0.01 \mathrm{mM}$ IPTG for 2.5 hours at $37^{\circ} \mathrm{C}$, cells were collected and lysed in buffer $(50 \mathrm{mM}$ Tris- $\mathrm{Cl} \mathrm{pH} 7.5$, $150 \mathrm{mM} \mathrm{NaCl}, 0.05 \% \mathrm{NP}-40$ ). Recombinant protein were batch purified using glutathione-sepharose beads. GST-SETD6 was purified similarly, but from Sf9 insect cells as described (15).

In vitro KMT and Flashplate KMT assays. Lysine methylation assays were performed in reaction buffer (50mM Tris-Cl pH8.0, $10 \%$ glycerol, $20 \mathrm{mM} \mathrm{KCl,} 5 \mathrm{mM}$ $\mathrm{MgCl}_{2}$ ) supplemented with ${ }^{3} \mathrm{H}-\mathrm{SAM}$ as described (8), using calf thymus histones (Worthington), recombinant histone tails (see above), or biotinylated histone H4 peptides.

Motif search. The GKDS sequence was used in a motif search using PHI-BLAST against the Non-redundant protein sequences (nr) database, restricted to Homo sapiens (taxid:9606).

\section{ACKNOWLEDGMENTS}

OB is supported by the Newcastle's Biomedical Fellowship Programme, which is in part funded through the Wellcome Trust's Institutional Strategic Support Fund, and by the Breast Cancer Campaign charity grant number 2013MaySP005.

\section{REFERENCES}

1. Allfrey, V., Faulkner, R., and Mirsky, A. (1964) Acetylation and Methylation of Histones and their Possible Role in the Regulation of RNA Synthesis, Proceedings of the National Academy of Sciences 51, 786-794.

2. Murray, K. (1964) The Occurrence of e-NMethyl Lysine in Histones, Biochemistry 3, 10-15.

3. Rea, S., Eisenhaber, F., O'Carroll, D., Strahl, B. D., Sun, Z.-W., Schmid, M., Opravil, S., Mechtler, K., Ponting, C. P., Allis, C. D., and 
Jenuwein, T. (2000) Regulation of chromatin structure by site-specific histone H3 methyltransferases, Nature 406, 593-599.

4. Binda, O. (2013) On your histone mark, SET, methylate!, Epigenetics 8, 457-463.

5. Chuikov, S., Kurash, J. K., Wilson, J. R., Xiao, B., Justin, N., Ivanov, G. S., McKinney, K., Tempst, P., Prives, C., Gamblin, S. J., Barlev, N. A., and Reinberg, D. (2004) Regulation of p53 activity through lysine methylation, $\mathrm{Na}$ ture 432, 353-360.

6. Huang, J., Perez-Burgos, L., Placek, B. J., Sengupta, R., Richter, M., Dorsey, J. A., Kubicek, S., Opravil, S., Jenuwein, T., and Berger, S. L. (2006) Repression of p53 activity by Smyd2-mediated methylation, Nature 444, 629-632.

7. Shi, X., Kachirskaia, I., Yamaguchi, H., West, L. E., Wen, H., Wang, E. W., Dutta, S., Appella, E., and Gozani, O. (2007) Modulation of p53 function by SET8-mediated methylation at lysine 382, Mol Cell 27, 636-646.

8. Binda, O., LeRoy, G., Bua, D. J., Garcia, B. A., Gozani, O., and Richard, S. (2010) Trimethylation of histone $\mathrm{H} 3$ lysine 4 impairs methylation of histone $\mathrm{H} 3$ lysine 9: regulation of lysine methyltransferases by physical interaction with their substrates, Epigenetics 5, 767-775.

9. Saddic, L. A., West, L. E., Aslanian, A., Yates, J. R. r., Rubin, S. M., Gozani, O., and Sage, J. (2010) Methylation of the retinoblastoma tumor suppressor by SMYD2, J Biol Chem 285, 37733-37740.

10. Estève, P.-O., Chin, H. G., Benner, J., Feehery, G. R., Samaranayake, M., Horwitz, G. A., Jacobsen, S. E., and Pradhan, S. (2009) Regulation of DNMT1 stability through SET7mediated lysine methylation in mammalian cells, Proc Natl Acad Sci USA 106, 5076-5081.

11. LeRoy, G., Weston, J. T., Zee, B. M., Young, N. L., Plazas-Mayorca, M. D., and Garcia, B. A. (2009) Heterochromatin protein 1 is extensively decorated with histone code-like posttranslational modifications, Mol Cell Proteomics 8, 2432-2442.

12. Lee, J. S., Kim, Y., Bhin, J., Shin, H.-J. R., Nam, H. J., Lee, S. H., Yoon, J.-B., Binda, O., Gozani, O., Hwang, D., and Baek, S. H. (2011) Hypoxia-induced methylation of a pontin chromatin remodeling factor, Proc Natl Acad Sci USA 108, 13510-13515.

13. Lee, J. S., Kim, Y., Kim, I. S., Kim, B., Choi, H. J., Lee, J. M., Shin, H.-J. R., Kim, J. H., Kim, J.-Y., Seo, S.-B., Lee, H., Binda, O., Gozani, O., Semenza, G. L., Kim, M., Kim, K. I., Hwang, D., and Baek, S. H. (2010) Nega- tive regulation of hypoxic responses via induced Reptin methylation, Mol Cell 39, 71-85.

14. Levy, D., Kuo, A. J., Chang, Y., Schaefer, U., Kitson, C., Cheung, P., Espejo, A., Zee, B. M., Liu, C. L., Tangsombatvisit, S., Tennen, R. I., Kuo, A. Y., Tanjing, S., Cheung, R., Chua, K. F., Utz, P. J., Shi, X., Prinjha, R. K., Lee, K., Garcia, B. A., Bedford, M. T., Tarakhovsky, A., Cheng, X., and Gozani, O. (2011) Lysine methylation of the NF-KB subunit RelA by SETD6 couples activity of the histone methyltransferase GLP at chromatin to tonic repression of NF-kB signaling, Nature Immunology 12, 29-36.

15. Binda, O., Sevilla, A., LeRoy, G., Lemischka, I. R., Garcia, B. A., and Richard, S. (2013) SETD6 monomethylates H2AZ on lysine 7 and is required for the maintenance of embryonic stem cell self-renewal, Epigenetics 8 , 177-183.

16. Vershinin, Z., Feldman, M., Chen, A., and Levy, D. (2016) PAK4 methylation by SETD6 promotes the activation of the Wnt/betacatenin pathway, $\mathrm{J}$ Biol Chem.

17. Eirew, P., Steif, A., Khattra, J., Ha, G., Yap, D., Farahani, H., Gelmon, K., Chia, S., Mar, C., Wan, A., Laks, E., Biele, J., Shumansky, K., Rosner, J., McPherson, A., Nielsen, C., Roth, A. J. L., Lefebvre, C., Bashashati, A., de Souza, C., Siu, C., Aniba, R., Brimhall, J., Oloumi, A., Osako, T., Bruna, A., Sandoval, J. L., Algara, T., Greenwood, W., Leung, K., Cheng, H., Xue, H., Wang, Y., Lin, D., Mungall, A. J., Moore, R., Zhao, Y., Lorette, J., Nguyen, L., Huntsman, D., Eaves, C. J., Hansen, C., Marra, M. A., Caldas, C., Shah, S. P., and Aparicio, S. (2015) Dynamics of genomic clones in breast cancer patient xenografts at single-cell resolution, Nature $518,422-426$.

18. O'Neill, D. J., Williamson, S. C., Alkharaif, D., Monteiro, I. C. M., Goudreault, M., Gaughan, L., Robson, C. N., Gingras, A.-C., and Binda, O. (2014) SETD6 controls the expression of estrogen-responsive genes and proliferation of breast carcinoma cells, Epigenetics 9, 942950.

19. Cohn, O., Chen, A., Feldman, M., and Levy, D. (2016) Proteomic analysis of SETD6 inter acting proteins, Data in brief 6, 799-802.

20. Wang, H., Cao, R., Xia, L., Erdjument-Bromage, H., Borchers, C., Tempst, P., and Zhang, Y. (2001) Purification and functional characterization of a histone H3-lysine 4-specific methyltransferase, Mol Cell 8, 1207-1217.

21. Kassner, I., Barandun, M., Fey, M., Rosenthal, F., and Hottiger, M. O. (2013) Crosstalk 
between SET7/9-dependent methylation and ARTD1-mediated ADP-ribosylation of histone H1.4, Epigenetics \& chromatin 6, 1.

22. Hornbeck, P. V., Kornhauser, J. M., Tkachev, S., Zhang, B., Skrzypek, E., Murray, B., Latham, V., and Sullivan, M. (2012) PhosphoSitePlus: a comprehensive resource for investigating the structure and function of experimentally determined post-translational modifications in man and mouse, Nucleic acids research 40, D261-270.

23. Binda, O., Boyce, M., Rush, J. S., Palaniappan, K. K., Bertozzi, C. R., and Gozani, O. (2011) A chemical method for labeling lysine methyltransferase substrates, Chembiochem : a European journal of chemical biology 12, 330-334.

24. Tweedie-Cullen, R. Y., Reck, J. M., and Mansuy, I. M. (2009) Comprehensive mapping of post-translational modifications on synaptic, nuclear, and histone proteins in the adult mouse brain, Journal of proteome research 8 , 4966-4982.

25. Bonenfant, D., Towbin, H., Coulot, M., Schindler, P., Mueller, D. R., and van Oostrum, J. (2007) Analysis of dynamic changes in post-translational modifications of human histones during cell cycle by mass spectrometry, Mol Cell Proteomics 6, 1917-1932.

26. Lee, Y. J., Rice, R. H., and Lee, Y. M. (2006) Proteome analysis of human hair shaft: from protein identification to posttranslational modification, Mol Cell Proteomics 5, 789-800.

27. Van Aller, G. S., Reynoird, N., Barbash, O., Huddleston, M., Liu, S., Zmoos, A.-F., McDevitt, P., Sinnamon, R., Le, B., Mas, G., Annan, R., Sage, J., Garcia, B. A., Tummino, P. J., Gozani, O., and Kruger, R. G. (2012) Smyd3 regulates cancer cell phenotypes and catalyzes histone $\mathrm{H} 4$ lysine 5 methylation, Epigenetics 7, 340-343.

28. Lu, A., Zougman, A., Pudelko, M., Bebenek, M., Ziolkowski, P., Mann, M., and Wisniewski, J. R. (2009) Mapping of lysine monomethylation of linker histones in human breast and its cancer, Journal of proteome research 8, 4207-4215. 